\title{
High precision machining of a displacement sensor for helicoidal motions
}

\section{Zeina ELRAWASHDEH ( $\boldsymbol{\nabla}$ zeina.elrawashdeh@icam.fr)}

Icam Site de Grand Paris Sud https://orcid.org/0000-0001-9340-3017

\section{Philippe REVEL}

Université de Technologie de Compiègne

\section{Christine PRELLE}

Université de Technologie de Compiègne

\section{Frédéric LAMARQUE}

Université de Technologie deCompiègne

\section{Research Article}

Keywords:

Posted Date: November 1st, 2022

DOI: https://doi.org/10.21203/rs.3.rs-915871/v2

License: (c) (1) This work is licensed under a Creative Commons Attribution 4.0 International License. Read Full License 


\title{
High precision machining of a displacement sensor for helicoidal motions
}

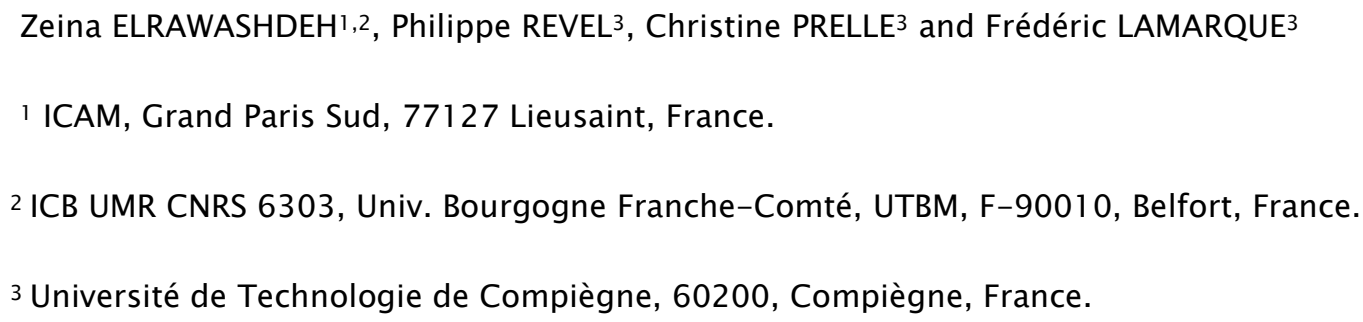

\begin{abstract}
This research study presents the design and the high precision manufacture procedure of a fiber-optic displacement sensor. It is composed of two fiber-optic probes associated with a structure of a cones' grating. The sensor is characterized by its ability to measure the linear displacement for an axis performing a helicoidal motion. This motion has been demonstrated on a high precision lathe; where the spindle provided the rotational motion, associated to a translational motion on the linear stage. This allowed to obtain the two simultaneous motions. The displacement of the translational stage is measured by the sensor in real time.
\end{abstract}

Firstly, a highly precise geometric model of the reflector part for the sensor was developed. This model provided a specific geometry for the cones-assembled grating, which has been precisely manufactured. The geometric parameters and the surface characteristics of each step in the fabricated grating were both identified in situ on the lathe. The agreement between simulation and experimental results is 
excellent. The performances of the fiber-optic displacement sensor were identified in-situ on the lathe. The analysis of the voltage output signals from the two fiberoptic probes is used to measure the grating displacement. The unbalanced rotation due to non-centered axes was also characterized. The sensor provided a micrometric resolution, on a measurement range of more than one centimeter.

Key words: high precision/ diamond tool machining/ fiber-optic/ sensor/ resolution/ measurement range. 


\section{Nomenclature}

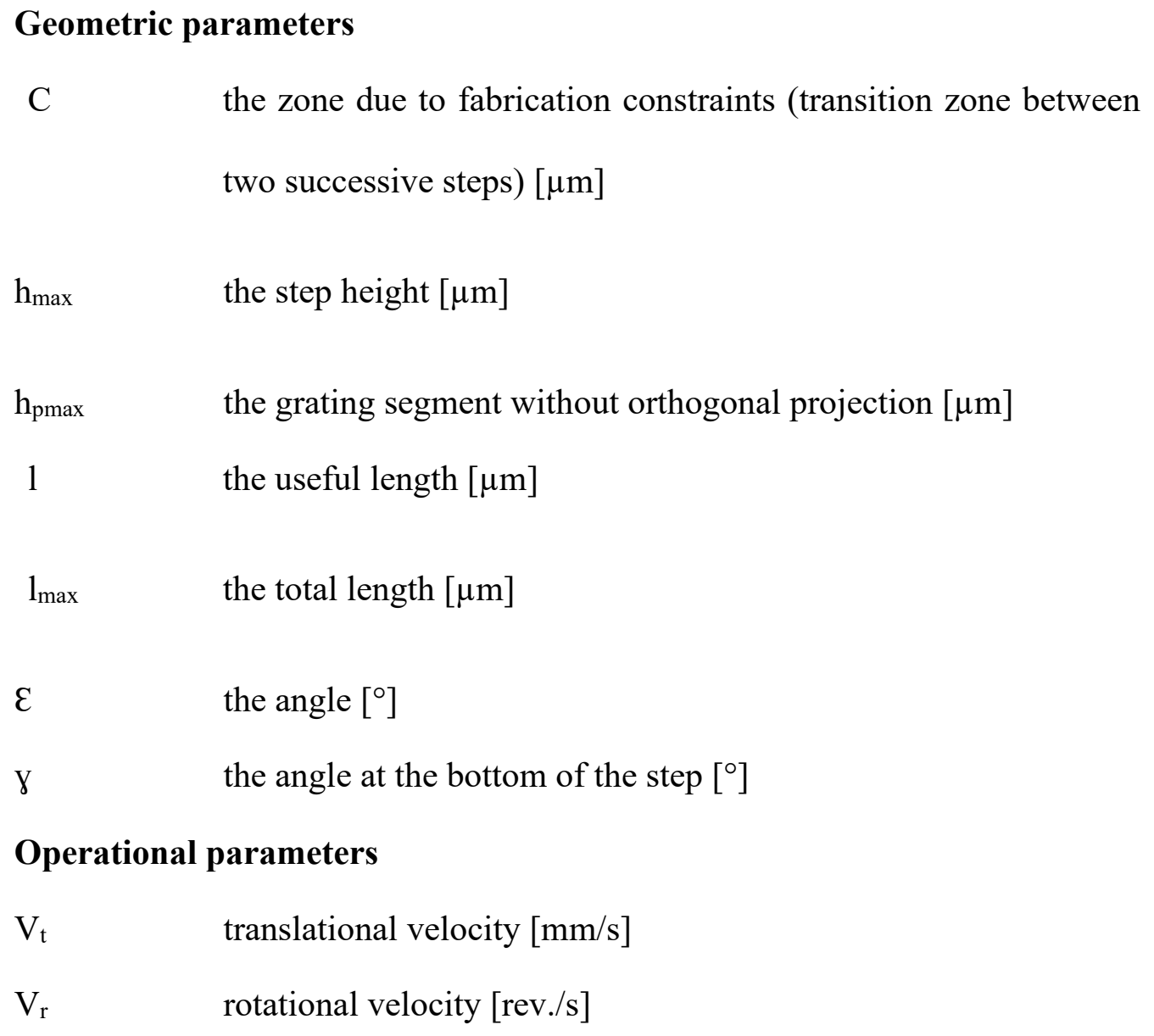

\section{Introduction}

Nowadays, the needs of high precision machining operations, with high accuracy in terms of geometry and surface roughness, are becoming essential in the production industry. Precision machining is found in a variety of sectors, including electronics, aircraft, and healthcare. Precision engineering is, as well, unavoidable for industrial automation, which takes into account, various sensing and control techniques [1]. In-line sensing techniques are now the ones widely spread, as they allow to take instantaneous measurements in the process line, using a probe. On- 
machine measurements are required for fast and accurate defect inspection in manufacturing systems without reducing production rates; the study presented by T. Santoso et. al. [2] illustrates the design and the development of a compact focus variation microcopy sensor that can be integrated into various types of machine tools, the sensor proved an accuracy of $2 \mu \mathrm{m}$, along with a measurement noise of $0.4 \mu \mathrm{m}$, an on-machine sensor measures the position and tilt of a workpiece in the machine tool before machining and measures the machining results for comparison with the design. The research paper illustrated in [3], presents an on-machine measurement device based on a chromatic confocal sensor, it is characterized by its ability to inspect workpiece surfaces with large slopes and depths. There have recently been several developments in the field of on-machine optical measuring instruments [4-8]. Those studies proved high precision in terms of resolution and repeatability for in situ measurements.

In addition, non-contact type sensors have been necessary in different types of measurement systems; as the contact-type ones take long time to measure, because the sensor must move toward the workpiece slowly, which might lead to the risk of scratching the surface of the workpiece.

Optical sensors have been largely developed as a non-contact type sensors on machine tools, thanks to their several advantages, such as: high sensitivity, good reproducibility, real time measurements, strong anti-interference ability and wide detection range [9]. The study presented in [10], illustrates a measurement set-up consisting of a non-contact single-sensor system and a signal processing algorithm for measuring the vibrational behavior inside of a CNC milling machine with a 
known force, it enables in-situ vibration measurements with a resolution below 230 $\mu \mathrm{m}$ and a displacement uncertainty down to $40 \mathrm{~nm}$. Another study presented by $\mathrm{F}$. Zhou et. al. [11], proposes a method to monitor the machining depth during the electrochemical machining process using an optical fiber, The fiber was inserted and fixed coaxially in the center of the tool electrode with its axis perpendicular to the surface of the workpiece, and an Fabry-Perot cavity formed between the fiber tip and the workpiece was used to monitor the machining depth. By analyzing the reflected spectrum, the inter-electrode gap was calculated. The sensing mechanism was discussed in depth, and two different methods to obtain the interelectrode gap was introduced. One of the methods has a theoretical precision of $4.45 \mathrm{~nm}$, but a time-consuming spectrum alignment process is required. Another method can use a simple program but has a lower theoretical precision of $2.16 \mu \mathrm{m}$, and a precision of $11.05 \mu \mathrm{m}$ during the experiment. The research study presented by S. Takushima et. al. [12] proposed a multi-directional laser displacement sensor using a scanning exposure method, it detects, and averages reflected light from many positions onto a workpiece, during the exposure time of an image sensor, the accuracy is at $\pm 1 \mu \mathrm{m}$.

Reduction of machining error enables higher dimensions accuracy in Computerized Numerical Control (CNC) machines, where the positioning error results in a contour error on the machined part. The paper presented by Jonathan Abir et. al. [13] presented the development of a virtual metrology frame technique to achieve high dynamic performance, as though the machine has a separate stiff metrology frame, by measuring machine frame displacement using an acceleration sensor. There are some recent studies in the literature, in which the helical shape 
configuration has been considered; the paper presented by Yanlin He et. al. [14], demonstrates the curvature and force measurement of a hyper elastic soft manipulator with helically embedded stretchable fiber-optic Bragg grating; the unique helically configuration prevents sensor dislocation, supports stretchability and facilitates the detection of various movements of the soft manipulator.

The current research study aims to develop a displacement sensor with high performances, in terms of its corresponding measurement range and the resolution. The sensor is characterized by its miniature size, as well as its ability to perform online measurements on rotating axes; such as spindles in machining operations, with sub-micrometric resolution on millimetric ranges. The sensor is composed of two fiber-optic probes associated with a cones' assembled grating. The grating has been manufactured on a high precision lathe along with a single crystal diamond tool on aluminium alloy, which allowed to obtain the desired geometry for the grating.

Optical sensors based on fibers are the ones used in this study, because of several advantages, such as small size, hard environment tolerance, impact of electromagnetic fields, flexibility and the structural simplicity $[15,16]$.

The state of art revealed high performances for linear displacement fiber-optic sensors associated only to the translational motion, from where appears the importance of the current sensor, characterized by its ability to measure the linear displacement associated to rotating elements. 
The following paragraph presents the measurement principle of the sensor and its reflector part, in addition to the adopted machining process. Finally the study presents the experimental validation of the measurement principle of the sensor insitu on a high precision lathe.

\section{Measurement principle}

This part presents the adopted strategy for the design and the high-precision fabrication method of the sensor. This sensor consists of two fiber-optic probes associated to a 3-dimensional reflective grating of aluminium alloy. The following paragraph introduces the sensor principle.

\subsection{Sensor principle}

The optical fiber used in this study consists of an electronic system, of fiber-optic probes (assembly of one central emission fiber and four reception fibers placed in periphery, the overall fibers are placed in the same support), along with a mirror reflecting the light. The electronic system consists of a light transmitter, a light emitting diode (LED), which sends light in a wavelength of about $670 \mathrm{~nm}$, with a numerical aperture of 0.17 , this numerical aperture of the LED is defined as the sine of the half aperture angle " $\mathrm{u}$ " $\left(\mathrm{u}=10^{\circ}\right)$ of the light emitting diode. The second component of the electronic system is the photodiode (Ph.D.), having an active detection zone of $1 \mathrm{~mm}$ diameter. These two components are integrated into a 
synchronous detection making it independent of the ambient luminous intensity, which could influence the measures.

The five optical fibers are multimode step index in polymethyl (PMMA) and are assembled in a steel ferrule, having a diameter of $2 \mathrm{~mm}$ (OMRON Company [1]). In the fiber-optic probe, the emission fiber is placed at the center, it has a diameter of $(486 \pm 5) \mu \mathrm{m}$ and a numerical aperture of 0.46 ; each of the four reception fibers has a diameter of $(240 \pm 5) \mu \mathrm{m}$, with a numerical aperture identical to that of the emission fiber. In the first study, the reflector has been a flat surface as shown in the following figure.

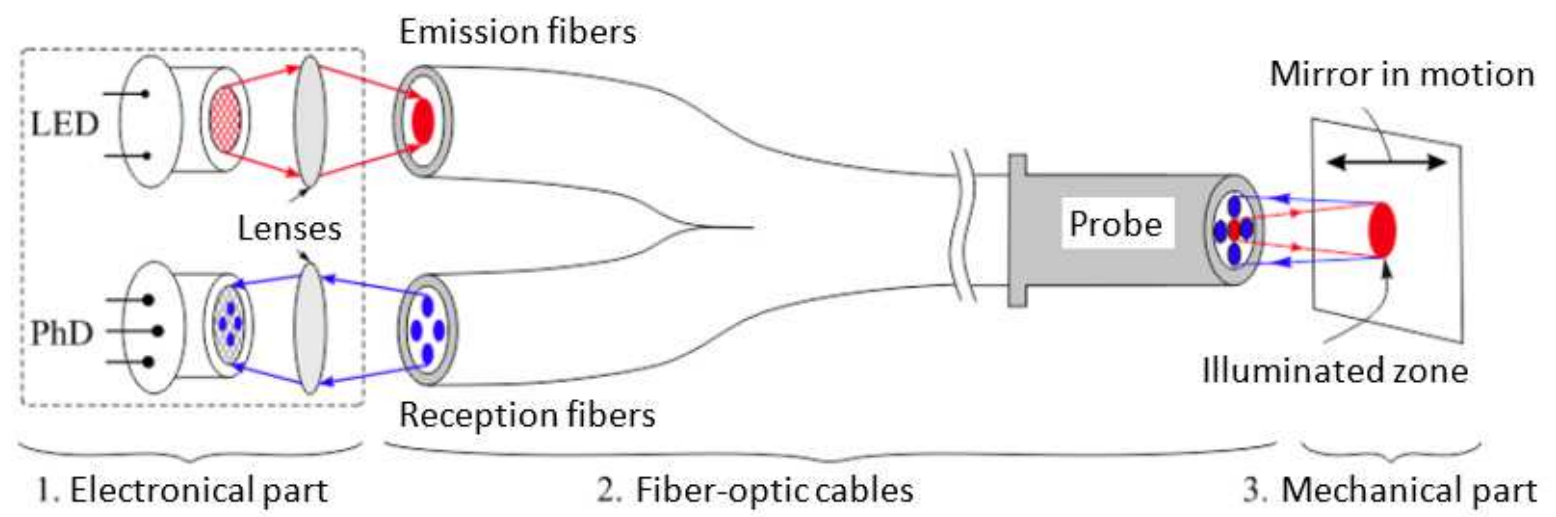

Figure 1 : Measurement principle of the fiber optic sensor [17].

The functionality principle of the sensor is based on light injection into an emission fiber, which illuminates the planar mirror in motion, relatively to the fiber-optic sensor, then to the detection of the reflected light. 
This injected light is guided by the emission fiber to the extremity of the probe , situated in front of the mirror. The emerging light of the probe is reflected by the mirror in translational motion, for which, the flatness of the surface is equal to $\lambda / 10$ $(\lambda €[400 \mathrm{~nm} ; 700 \mathrm{~nm}]$. A part of the reflected light is injected in the four reception fibers, then guided to the photodiode, which collects this light and then transforms it to an electric current. Having a perpendicular translation of the mirror axis with respect to the surface of the fiber-optic probe, the quantity of the collected light changes, and that provides a variation of the output voltage (Fig. 2 (a), (b)).

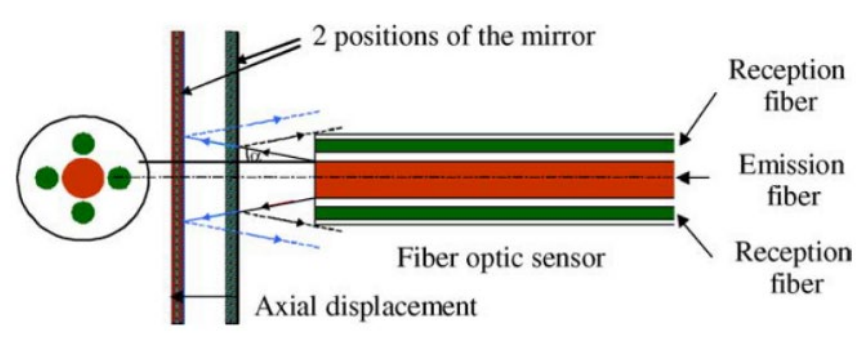

(a)

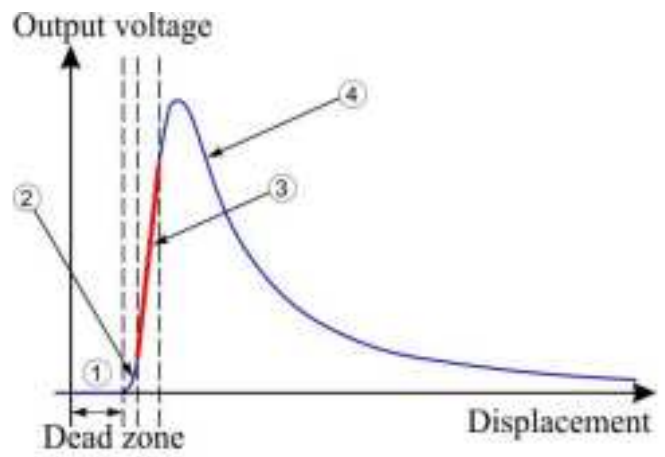

(b)

Figure 2. The optical fiber displacement sensor.

Figure $(2, b)$ shows the response curve of the sensor, as it is seen, this curve is formed of four zones. The first zone (zone 1) is the dead zone, where the sensor detects nothing, the mirror is still very close to the probe, and along with a separation of several dozens of micrometers between the emission fiber and the reception fibers, the reflected light of the mirror does not reach the reception fibers. The second zone (zone 2), corresponds to the zone where the sensor starts to detect the reflected light, but, the sensitivity is still very low. The third zone (zone 3 ) is 
the most important zone for linear displacements, as it has a high sensitivity with the best resolution; this high sensitivity is only available on a small range, approximately $200 \mu \mathrm{m}$, for a linearity criterion of $1 \%$ on the full scale voltage output $[0 ; 10 \mathrm{~V}]$. The last zone is zone 4 , which illustrates a voltage drop of the sensor output, and that happens when the mirror moves away from the probe , because the reflected light does not totally reach the reception fibers of the probe. So, it is always preferred to work in zone 3 , as it is a linear zone along with a high sensitivity [8]. However the measurement range of that zone, for the axial displacement is limited to $200 \mu \mathrm{m}$, which is not suitable for applications requiring large strokes. For that reason, and in order to increase this low measurement range, the displacement direction of the flat mirror should be different from the normal vector orientation of its surface resulting in a lateral displacement direction with an angle, defined in this study as $\varepsilon$, this new configuration has provided an inclined step with this defined angle (figure 3 ).

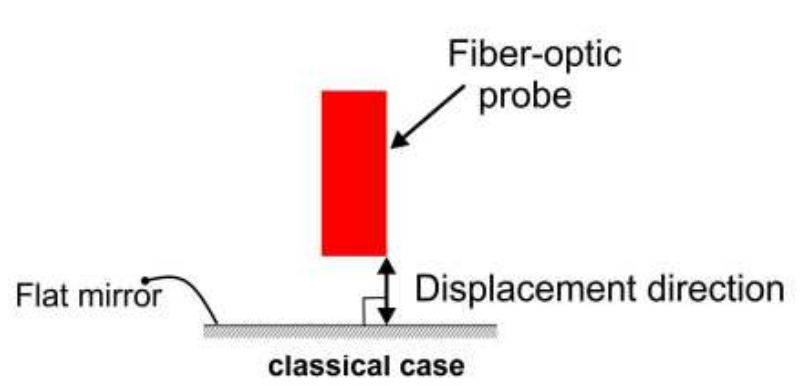

(a)

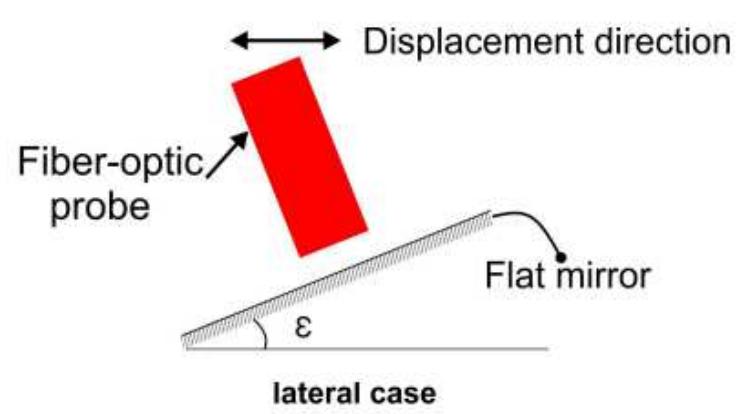

(b)

Figure 3 : Schematic diagrams for the displacement directions [18]. 
In this configuration of the inclined step, the classical axial measurement range $\left(\mathrm{MR}_{\text {axial }}\right)$ will increase by a factor of $(\sin \varepsilon)^{-1}$, giving a new lateral measurement range $\left(\mathrm{MR}_{\text {lateral }}\right)$ following this equation:

$$
\mathrm{MR}_{\text {lateral }}=\left(\frac{\mathrm{MR}_{\text {axial }}}{\sin \varepsilon}\right)
$$

At the same time, the lateral displacement congiguration modifies the values of the sensor sensitivity $\left(\mathrm{S}_{\text {axial }}\right)$ and its resolution $\left(\mathrm{R}_{\text {axial }}\right)$, as a function of $\sin \varepsilon$, which is explained in the following equations:

$$
\begin{aligned}
& S_{\text {lateral }}=S_{\text {axial }} \times \sin \varepsilon \\
& S_{\text {lateral }}=S_{\text {axial }} \times \sin \varepsilon
\end{aligned}
$$

This inclined step, has certain geometric parameters in addition to the angle $\varepsilon$, the following figure illustrates the inclined step, in addition to its corresponding geometric parameters: 


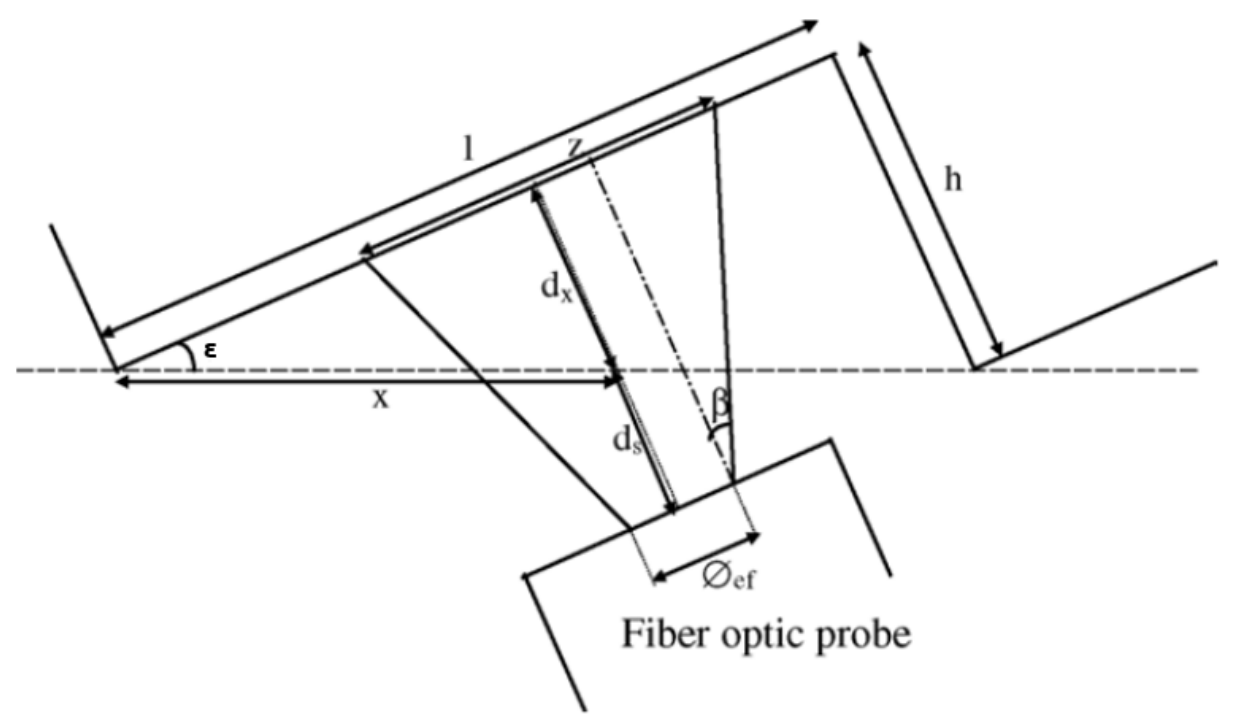

Figure 4 : Grating and emission fiber parameters [19].

The following table illustrates the signification of each parameter. 
Table 1: Geometric model parameters.

\begin{tabular}{|c|c|}
\hline Symbol & Quantity \\
\hline$\Phi e f(\mu \mathrm{m})$ & Emission fiber diameter \\
\hline$\Phi(\mu \mathrm{m})$ & Probe diameter \\
\hline$\beta$ & Emission fiber numerical aperture \\
\hline$d(\mu \mathrm{m})$ & Distance between probe head \& \\
& grating \\
\hline$d_{x}(\mu \mathrm{m})$ & Distance : x.sine \\
\hline$d_{s}(\mu \mathrm{m})$ & Security distance \\
\hline$\varepsilon\left({ }^{\circ}\right)$ & Grating angle \\
\hline$x(\mu \mathrm{m})$ & Lateral position \\
\hline$l(\mu \mathrm{m})$ & Step length \\
\hline$h(\mu \mathrm{m})$ & Step height \\
\hline$z(\mu \mathrm{m})$ & Illuminated zone diameter \\
\hline
\end{tabular}


The sensor performances are influenced by the geometric parameters of the grating. The geometric model considers the optimization of the sensor resolution $\mathrm{R}_{\varepsilon}$ (the resolution has to be as minimum as possible).

$$
R_{\varepsilon}=\frac{R}{\sin \varepsilon}
$$

Where $(\mathrm{R})$ is the limit of resolution of the sensor in the common use.

It can be deduced that $\varepsilon$ has to be large in order to decrease the sensor limit of resolution, we can also observe that :

$$
\tan \varepsilon=\frac{h}{l}
$$

So, the choice of the step length and height influence tha value of the sensor limit of resolution and measurement range.

This previous measurement configuration described in the previous figure cannot provide millimetric ranges with resolution in the order of tens of nanometers. To increase the range to several millimeters by preserving a good resolution, the inclined mirror configuration was duplicated; this duplication leads to a grating of successive flat mirrors. In the case of a grating of flat mirrors, two fiber-optic probes are used to avoid the transition between two consecutive steps (Figure 5) [16, 20]. 


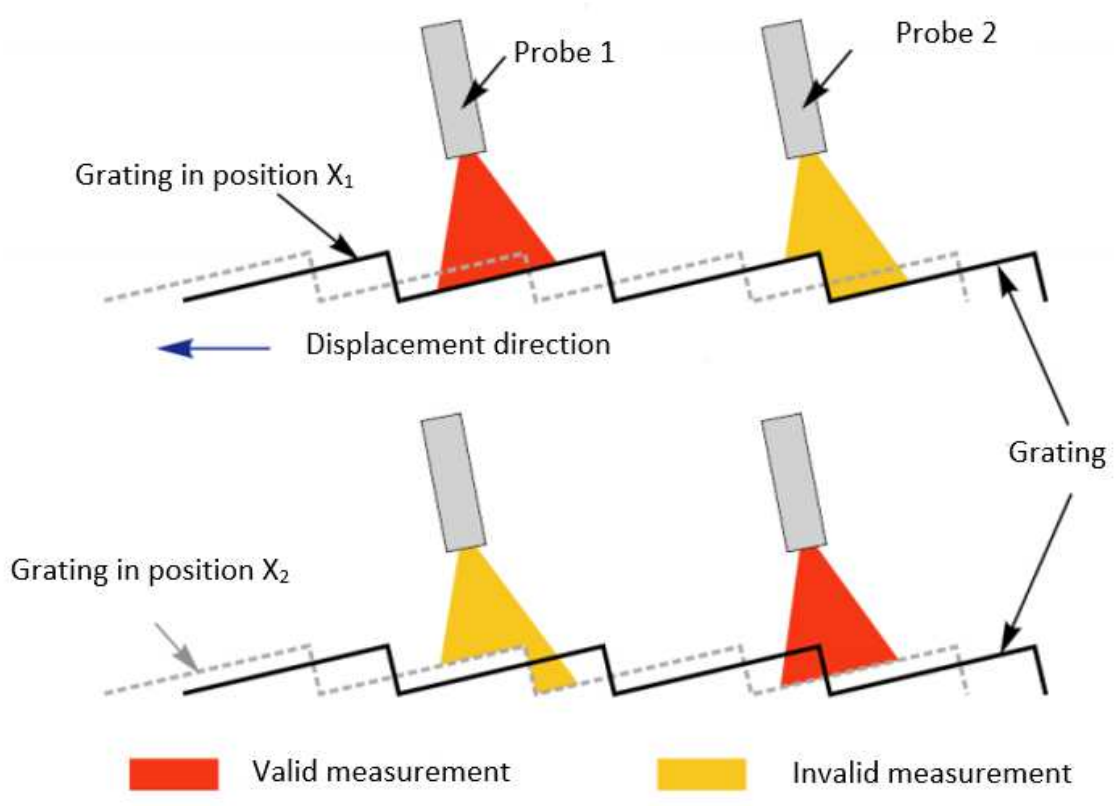

Figure 5. Long range sensor principle.

The objective of this work is the linear displacement measurement for a rotating axis, such as a spindle, over an extended range (minimum $10 \mathrm{~mm}$ ), without being disturbed by the rotational motion. For that reason, the sensor reflective grating has to have a 3D shape in order to provide a valid measurement even if the sensor rotates along its axis of symmetry. The schematic diagram of this grating associated to the fiber-optic probes is shown in the following figure. 


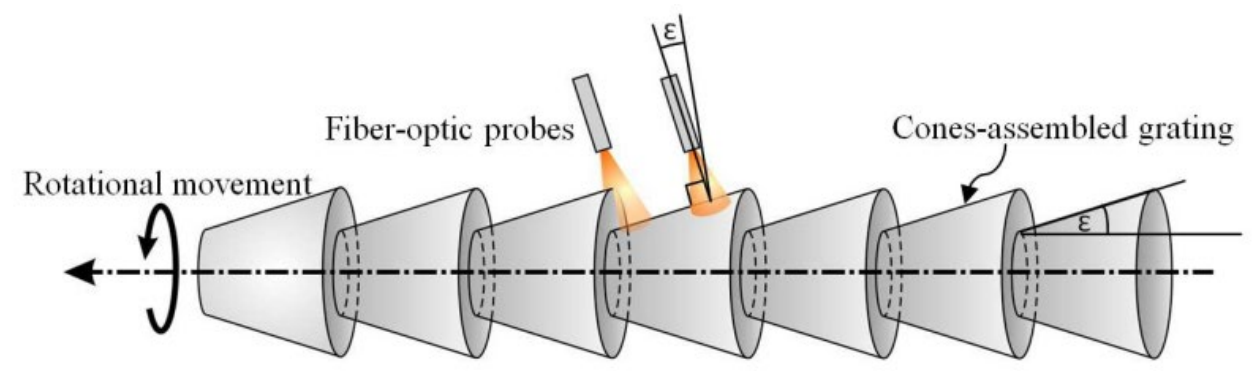

Figure 6. Schematic diagram of the cones' assembled grating associated to the fiber-optic probes [19].

\subsection{The design of the cones-assembled grating}

The reflector part of the sensor is a group of successive cones of certain properties and performances [9]. For that reason, a new design was developed to analyze the sensor response to curved reflectors. The research papers illustrated in $[21,22]$ present a full study of that model; for which, the response curve of the sensor at a fixed radius of curvature $\left(\mathrm{R}_{\mathrm{c}}\right)$, was obtained.

In the two previous studies mentioned in $[21,22]$, the influence of the curved reflector on the sensor performances was modelled. The surface of the reflector grating is convex. The property of having a convex reflector will modify the sensor performances as compared to the previous sensor with a flat mirror reflector. Different geometric parameters were considered, in order to observe the influence of the convex surface on the sensor performances. These parameters are shown in table 2 and figure 7. 
Table 2: Geometric model results.

\begin{tabular}{|c|c|}
\hline Symbol & definition \\
\hline$\varnothing(\mu m)$ & The probe diameter \\
\hline$R_{c}(m m)$ & The radius of curvature \\
\hline$M$ & The tangential point \\
\hline $\overrightarrow{M_{M}}$ & The normal vector to tangent \\
\hline$d_{0}(\mathrm{~mm})$ & $\begin{array}{l}\text { The initial distance between the } \\
\text { reflector and the probe }\end{array}$ \\
\hline$\alpha\left(^{\circ}\right)$ & The incidence angle \\
\hline$\delta\left({ }^{\circ}\right)$ & $\begin{array}{l}\text { The angle between nat and the } \\
\text { symmetrical axis of the probe }\end{array}$ \\
\hline$e(\mu m)$ & $\begin{array}{l}\text { The spacing between the emission } \\
\text { fiber and the reception fiber }\end{array}$ \\
\hline$\Delta(\mu m)$ & $\begin{array}{l}\text { The spacing between the normal } \\
\text { vector of the flat surface and the } \\
\text { reflected beam from the curved } \\
\text { surface intercepted by the sensor }\end{array}$ \\
\hline
\end{tabular}




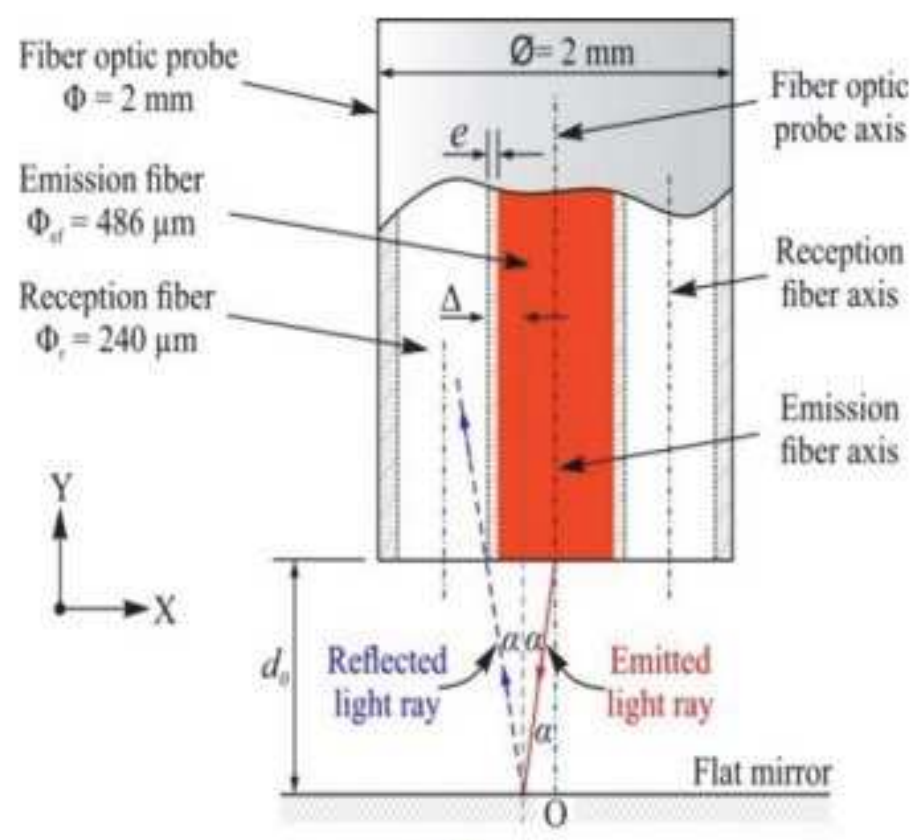

(a)

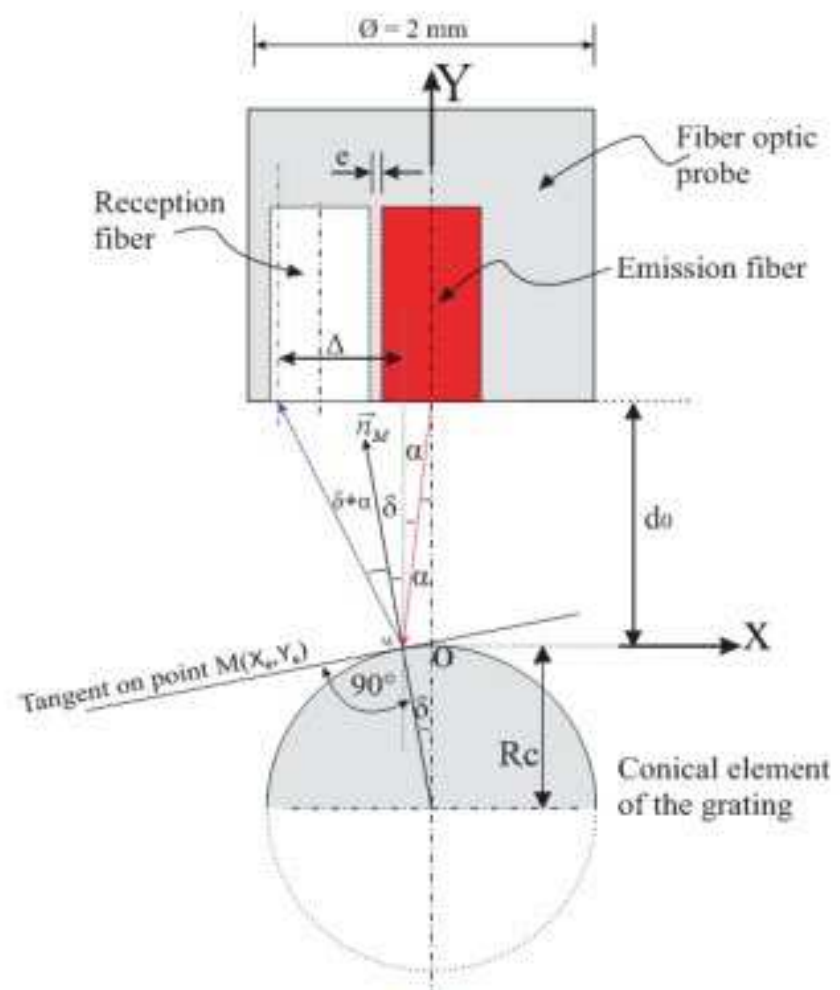

(b)

Figure 7. Schematic diagram of the reflected light model (a) flat mirror, (b) convex mirror [22]. 
The flat mirror configuration was used as a reference, it was found out that the higher the radius of curvature is, better will be the nomalised light intensity detected in the linear part of the curve, and in consequence, better will be the performance of the sensor. The following figure presents the results of different radii of curvature $\left(\mathrm{R}_{\mathrm{c}}\right)$ as a function of the displacement $\left(\mathrm{d}_{0}\right)$.

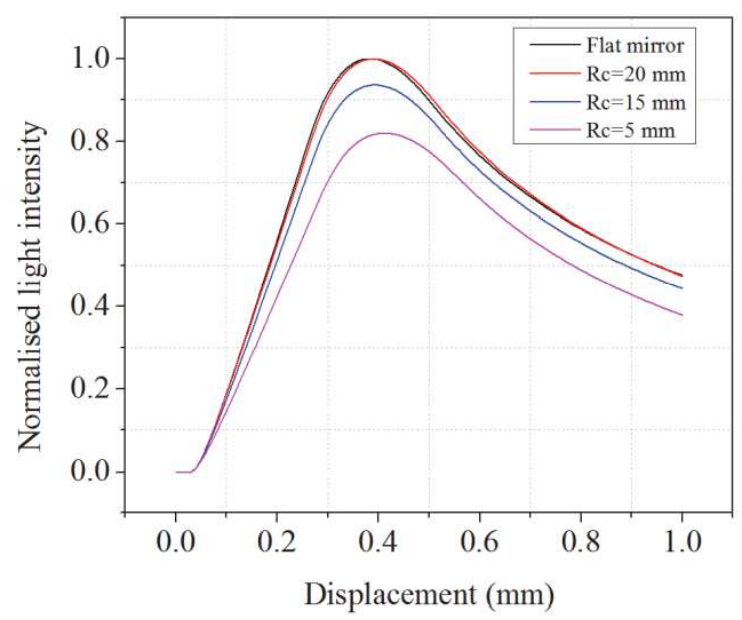

Figure 8. Schematic diagram of the reflected light model (a) flat mirror, (b) convex mirror [21].

The geometric model previously described has been validated experimentally by fabricating two pieces of cylinders with different diameters : piece (A) with small diameters $(40,30,20,10 \mathrm{~mm})$ and piece (B) with large diameters $(55,50,40,35$ $\mathrm{mm}$ ). These two pieces have been fabricated with a single crystal diamond tool on a high precision turning machine. For each cylinder in the two pieces, the calibration curve of the sensor has been obtained by moving the sensor away from the cylinder reflecting surface. The linear sensitivity has been calculated for each curve with a linearity criterion of $1 \%$. The following figure illustrates the experimental set-up used, it consists of the two reflecting pieces together with a fiber-optic probe. 


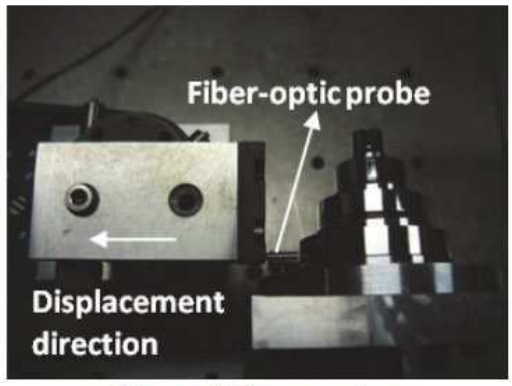

(A): small diameter piece

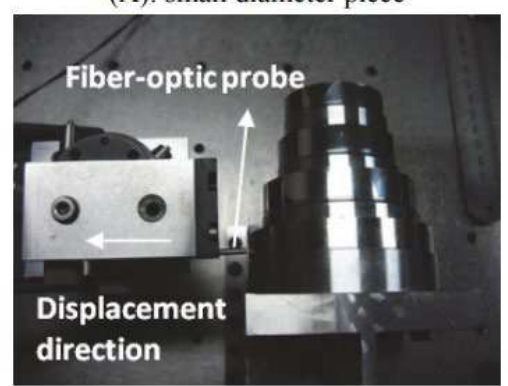

(B): large diameter piece

Figure 9. Schematic diagram of the reflected light model (a) flat mirror, (b) convex mirror [21].

The experimental sensitivities have been compared to the theoretical sensitivities (zone 3 of figure 2), in order to test the validity of the geometric model (figure 10).

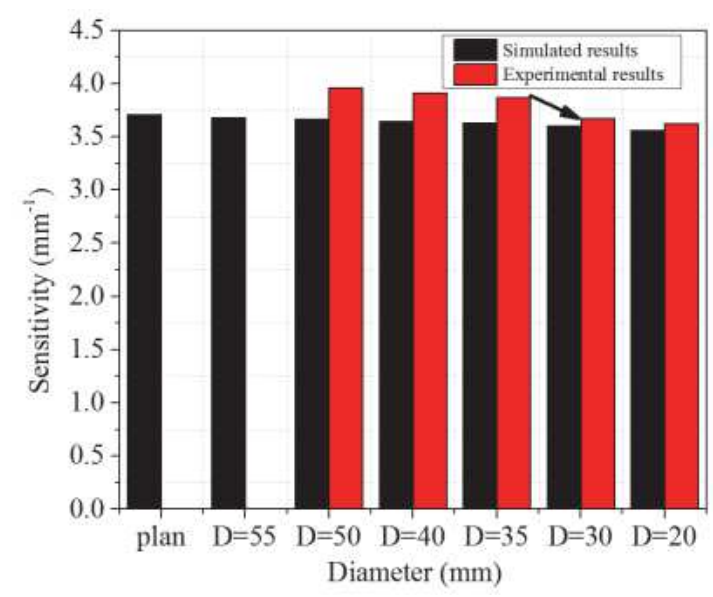

Figure 10. Influence of the diameter of the reflective convex surface on the sensor sensitivity [22]. 
A diameter of $50 \mathrm{~mm}$ has been chosen to fabricate the cones' assembled grating, in order to guarantee a good performance of the sensor. A first conical grating prototype has been fabricated and characterized geometrically.

After that, the long-range displacement operation with the conical grating was simulated with a second geometric design.

The geometric model of the cones-assembled grating provided the geometric parameters necessary for a proper functionality for the sensor.

The following figure illustrates the geometric design for one step of the conesassembled grating.

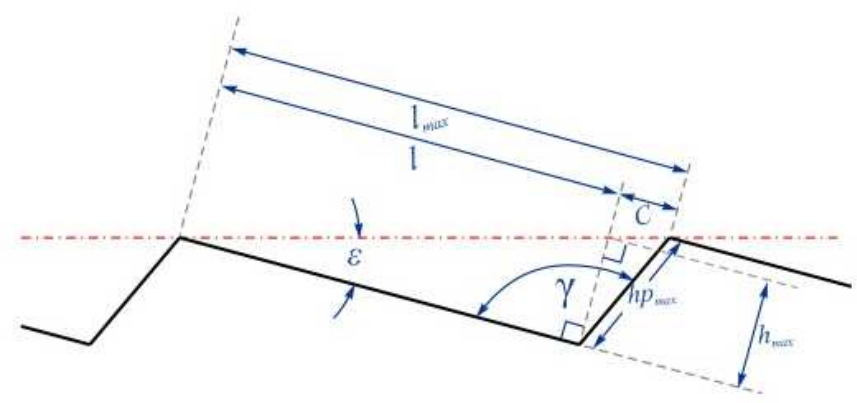

Figure 11. Geometric parameters of one step in the cones' assembled grating.

The previously described design provided an optimal value for each parameter, as shown in table 3. 
Table 3: Geometric model results.

\begin{tabular}{|c|c|}
\hline $\begin{array}{c}\text { Geometric } \\
\text { parameter }\end{array}$ & $\begin{array}{c}\text { Numerical } \\
\text { value }\end{array}$ \\
\hline $1(\mu \mathrm{m})$ & 1478 \\
\hline $\mathrm{C}(\mu \mathrm{m})$ & 100 \\
\hline $1_{\max }(\mu \mathrm{m})$ & 1578.1 \\
\hline $\mathrm{h}_{\max }(\mu \mathrm{m})$ & 119 \\
\hline $\mathrm{h}_{\mathrm{pmax}}(\mu \mathrm{m})$ & 155.34 \\
\hline$\varepsilon\left(^{\circ}\right)$ & 4.60 \\
\hline$\gamma\left(^{\circ}\right)$ & 130 \\
\hline
\end{tabular}

For this model, the angle $\gamma$ was fixed at $130^{\circ}$. This angle should be higher than $90^{\circ}$, in contrary to the grating developed in the previous study, for which the angle was fixed at $90^{\circ}$ (figure 4), and this is due to the tool footprint on the surface of the grating, which is suitable for the fabrication process.

The values of the parameter 1 and $h_{\max }$ were respectively $1478.1 \mu \mathrm{m}$ and $119 \mu \mathrm{m}$. The angle $\varepsilon$ and the segment $h p_{\max }$ are deduced geometrically as shown in the following equations:

$$
\begin{gathered}
\varepsilon=\operatorname{atan}\left(\frac{\mathrm{h}_{\text {max }}}{\mathrm{l}}\right) \\
\mathrm{h} \mathrm{p}_{\max }=\mathrm{h}_{\max } /\left(\cos \left(\gamma-90^{\circ}\right)\right)
\end{gathered}
$$

As explained previously, the geometric parameters influence the sensor resolution regarding the resolution, the measurement range and the sensitivity. 
The cones-assembled grating has high requirements, regarding the precision of the geometric dimensions and the necessity of very low surface roughness. For those reasons, the grating has been manufactured with a high precision machine and a single crystal diamond tool $[12,13]$.

\subsection{Machining process}

The following paragraph illustrates the fabrication procedure, which had been carried out using a high-precision lathe and a single crystal diamond tool on aluminium alloy.

\subsubsection{Characteristics of the high precision lathe and the machining tool}

The sensor sensitivity and resolution are improved by a high reflectivity factor $(\mathrm{R}$ $>95 \%)$ of the grating, which depends on a low roughness $(\mathrm{Ra}<10 \mathrm{~nm})$ and also of the flatness of each step in the grating. Besides, to ensure the highest linearity of

the sensor, the flatness has to be in the order of magnitude of $\frac{\lambda}{10}$ (optical quality), where $\lambda$ is the wavelength of the optical source. Finally, the length and the height of each step must be highly reproducible and very close to the geometric values provided by the geometrical model in order to ensure an accurate value of the angle 
$\varepsilon$. For those reasons, a high precision lathe was chosen, thanks to its adaptability to 3D axis-symmetrical pieces (Figure 12).

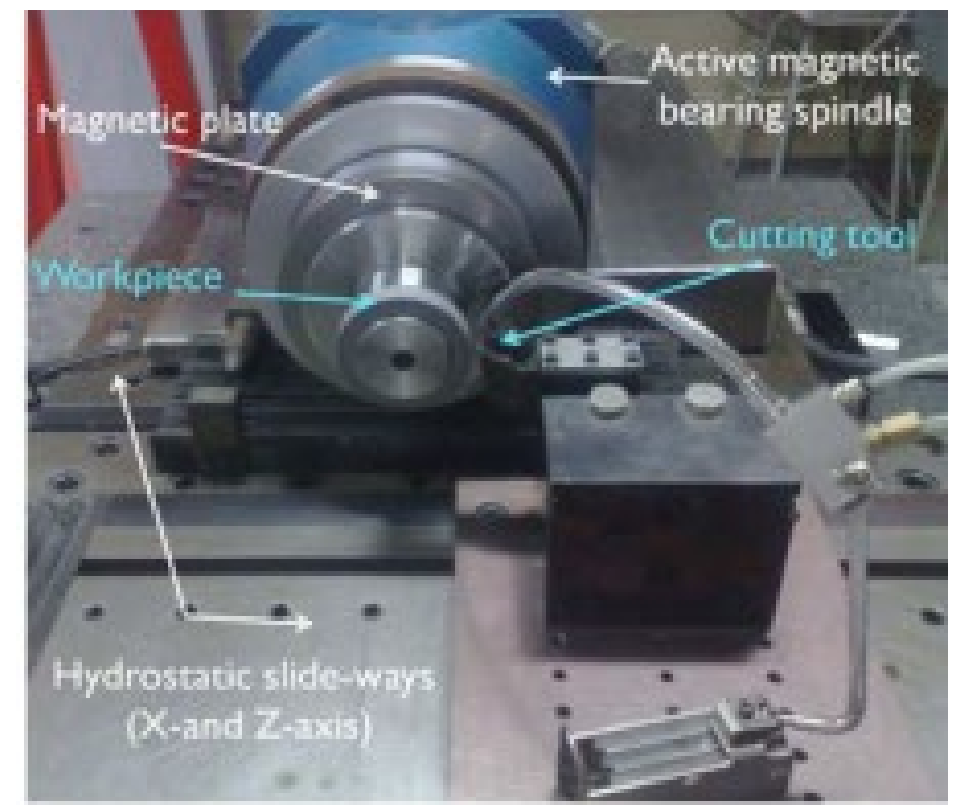

Figure 12. Focus on the high precision lathe used in this study [22]

This high precision machine is a prototype lathe, designed by Snecma ${ }^{\mathrm{TM}}$ Motor, as shown in figure 5. The two slideways (X-and $\mathrm{Z}$-axis) are guided by hydrostaticbearings offering high damping and high stiffness; fixed on a massive granite block (1.5 tonnes), which rests on four self-leveling pneumatic isolators. The straightness of both slides is better than $0.3 \mu \mathrm{m}$ over a displacement of $100 \mathrm{~mm}$. The rotating spindle is fixed on the Z-axis, along with magnetic bearings [12].

Despite the high performances of the lathe, some defaults have been identified and measured. These residual defaults are due to a small misalignment between the spindle axis of rotation and the Z-axis, on which the spindle is fixed, as well as a small perpendicularity misalignment between the $\mathrm{X}$-axis and the Z-axis. As a 
consequence, when a cylinder is fabricated, it will have a slight conical effect; with an increasing diameter, apart from the spindle side, the measured angle of this cone is approximately $0.014^{\circ}$. These defaults have been taken into account during the machining process and in the measurement of the geometrical parameters of the fabricated grating.

To get a cylinder with the smallest conical effect, this conical default should be compensated in the following manner: For $10 \mathrm{~mm}$ displacement of the Z-axis, 2.5 $\mu \mathrm{m}$ of the $\mathrm{X}$-axis should be shifted. This compensation has been considered while manufacturing the cones-assembled grating.

To obtain a polished-mirror characteristic for the cones-assembled grating (a nanometric roughness), a single-crystal diamond tool, with a small radius of curvature $(\mathrm{R}=100 \mu \mathrm{m})$, was used [23], as well as an aluminum alloy 2017 to fabricate the cones-assembled grating.

\subsubsection{The machining technique}

To get high surface qualities for the reflector part of the sensor, the depth cut has to be less than $10 \mu \mathrm{m}$ [22]. The manufacturing technique has two main stages: During the initial phase, the surface of the raw cylinder was dressed and turned. Lubrication with spray was added, which facilitates the cut process, and allows getting high surface roughness.

The second stage is the fabrication of the cones-assembled grating on the cylinder. This phase is done in two steps: firstly, every conical step has been fabricated with seven successive cuts, then, a finishing cut $\left(8^{\text {th }}\right.$ cut $)$ was done to get the 
corresponding shape of the cones-assembled grating. For each cone, two consecutive trajectories were programmed as previously explained in [19]. The depth of the six first cuts was fixed to $18 \mu \mathrm{m}$ while it was $10 \mu \mathrm{m}$ for the seventh.

Figure 13 shows the cones-assembled grating. The eighth cut allowed having a polished-mirror surface for the first five steps, whereas the last five steps which have not yet had the eighth cut are not reflective.

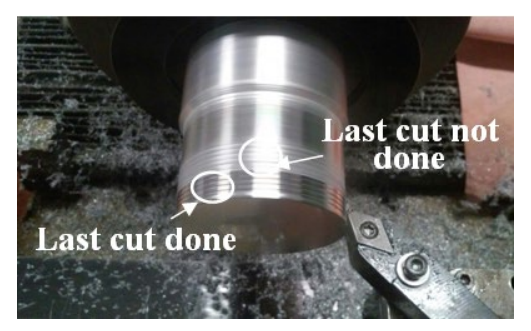

Figure 13. Manufacturing of the cones' assembled grating.

The high precision fabrication technique allowed getting the geometric parameters, obtained from the theoretical design. Then, it has been characterized geometrically using the Nanofocus ${ }^{\mathrm{TM}} \mu$ scan optical profilometer (figure 14). The steps profile was measured (figure 15) and compared with the theoretical dimensions (Table 4).

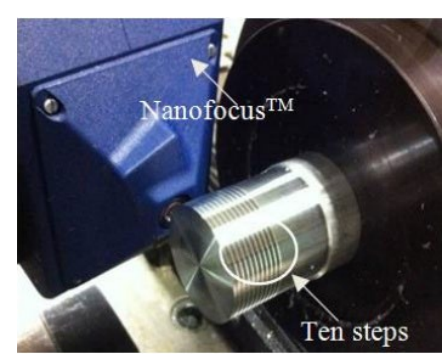

Figure 14. Geometric characteristics. 


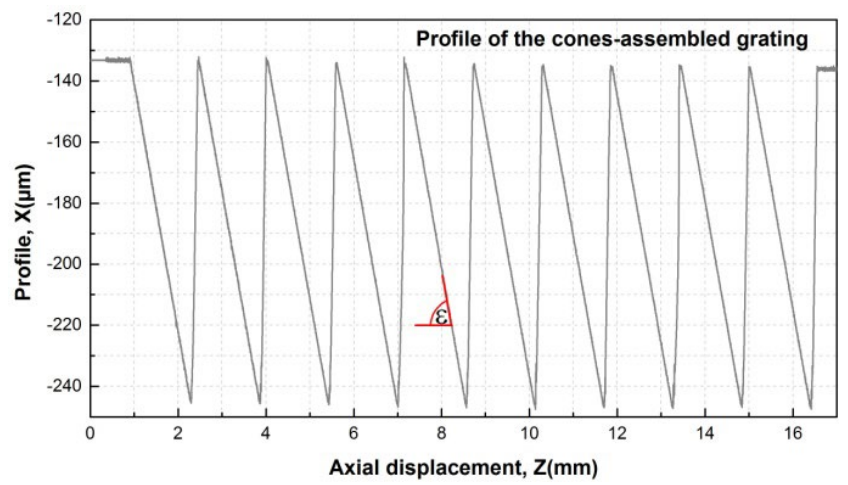

Figure 15. Profile of the measured steps after fabrication.

Table 4: Comparison between the theoretical values and the measured values for the geometric parameters of the cones-assembled grating.

\begin{tabular}{|c|c|c|c|}
\hline & Total length $(\boldsymbol{\mu m})$ & Step height $(\boldsymbol{\mu m})$ & $\mathcal{E}\left(^{\circ}\right)$ \\
\hline Simulation & 1578.1 & 119.0 & 4.60 \\
\hline Measurement & $1578.5 \pm 2.8$ & $115.3 \pm 1.2$ & $4.5 \pm 0.1$ \\
& & & \\
\hline
\end{tabular}

It is observed from these results, that the measured values are close to the theoretical ones; the percentage error for the step length is $0.02 \%$, concerning the step height, the failure is $3.11 \%$, and for the angle $\varepsilon$ the error is $2.17 \%$. 
The surface characteristics for the cones-assembled grating were identified using an interferometric microscope, which gave a roughness value of $(51.4 \pm 2.7) \mathrm{nm}$ and an average arithmetic roughness $(\mathrm{rms})$ of $(63 \pm 3.7) \mathrm{nm}$, which is suitable for high surface reflectivity. Figure 16 illustrates the surface characteristics for the first grating step $\left(\mathrm{R}_{\mathrm{a}}=53 \mathrm{~nm}\right.$, arithmetic roughness $\left.(\mathrm{rms})=71 \mathrm{~nm}\right)$.

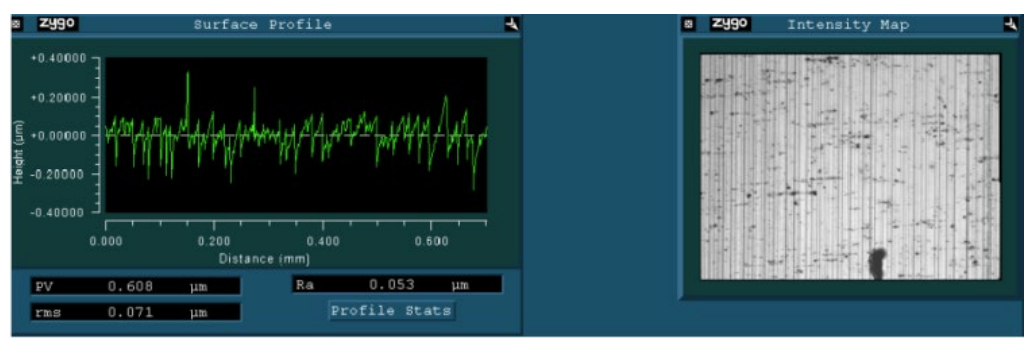

Figure 16. Surface characteristics.

\section{Results \& Discussion}

The following section illustrates the experimental validation of the sensor principle, for which the objective is to measure the linear displacement for a rotating spindle on a range of several millimeters with a sub-micrometric resolution.

\subsection{Experimental set-up}

The functionality of the optical fiber has to be validated. Firstly, the unbalanced rotation phenomenon has been characterized, by analyzing the sensor signals at 
different velocities, then the sensor performances have been evaluated, by taking into account its measurement range, the corresponding resolution, and also the overlap between the two fiber-optic probe signals.

An experimental set-up was designed and fixed in front of the cones-assembled grating (Fig. 17 (a)). The set-up is composed of two manual linear stages (4 and 5), one manual rotation stage (2) and one height adjustment linear stage (1). Each fiberoptic probe is fixed on a linear stage (3), perpendicularly to the cones surface, so that the displacement sensitivity is optimal (Fig. 10 (b)).

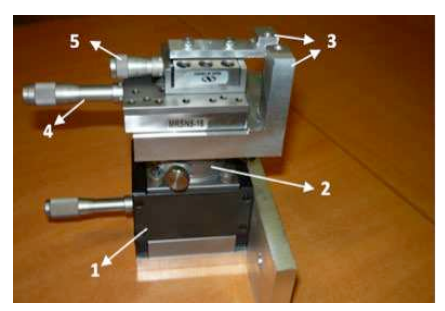

(a)

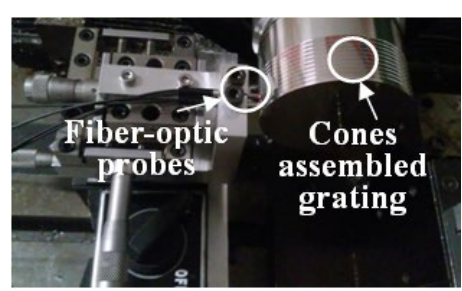

(b)

Figure 17. Experimental set-up.

To verify the functionality of the fiber-optic sensor, the conical grating was kept on the rotating axis of the machine, with the objective to produce a helicoidal motion, without introducing new positional errors. The grating displacement was done using the Z-axis of the lathe; the rotation was generated using the spindle. 


\subsection{Unbalanced rotation characterization}

The unbalanced rotation phenomenon due to off-centered axes (the rotation axis of the conical grating and the axis of rotation of the spindle), has been characterized with one fiber-optic probe. This phenomenon was observed by varying the velocity of the grating. The following signals have been obtained with $V_{t}$ ranged from 0.1 $\mathrm{mm} / \mathrm{s}$ to $0.5 \mathrm{~mm} / \mathrm{s}$, while $\mathrm{V}_{\mathrm{r}}$ has been fixed at $1 \mathrm{rev} . / \mathrm{s}$ (figure 18 ). The graph in red stands for $\mathrm{V}_{\mathrm{t}}=0.1 \mathrm{~mm} / \mathrm{s}$, whereas the one in black stands for $\mathrm{V}_{\mathrm{t}}=0.5 \mathrm{~mm} / \mathrm{s}$. 


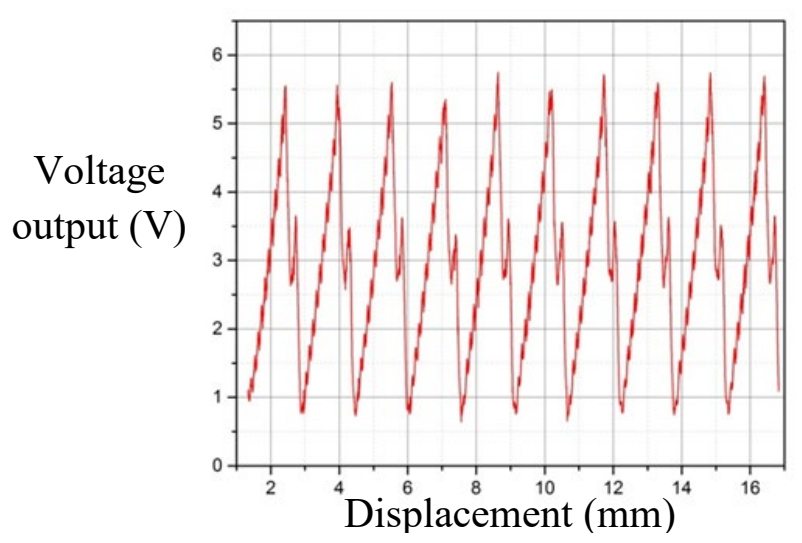

(a): $\mathrm{V}_{\mathrm{t}}=0.1 \mathrm{~mm} / \mathrm{s}$

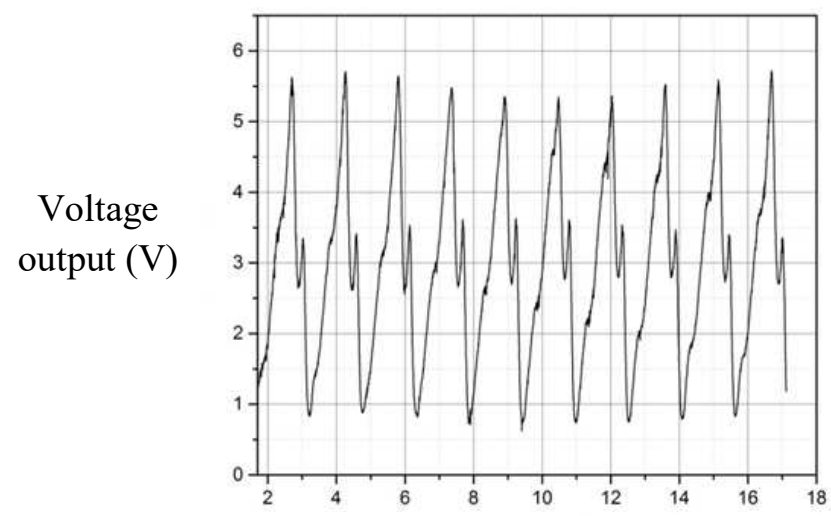

Displacement (mm)

(b) : $\mathrm{V}_{\mathrm{t}}=0.5 \mathrm{~mm} / \mathrm{s}$.

Figure 18. Voltage output signals of the fiber-optic sensor at two translational velocities.

As seen from the previous figure, there are periodic peaks in each signal. These peaks are due to the unbalanced rotation of the spindle; they have a period of $1 \mathrm{~s}$ (linked to $V_{r}=1$ rev. $/ \mathrm{s}$ ). By increasing the translational speed, the number of the peaks decreases. The reason is that at high translational velocities, the time needed 
for the spindle to make one complete turn is higher than the time required to cross the linear part of the voltage variation.

So, to avoid the unbalanced rotation phenomenon, high velocities should be applied.

\subsection{Long range displacement measurement}

Firstly, a translational velocity of $0.5 \mathrm{~mm} / \mathrm{s}$ was applied. The following figure presents an example of the two signals, where an overlap of $30 \mu \mathrm{m}$ was measured. The overlap criterion was fixed at a minimum value of $30 \mu \mathrm{m}$ as in previous studies. This overlap allowed switching between the signals, and not to generate measures in the non-linear zone; when the probe reaches the extremity end of the curve, and in consequence, to the defined the allowed linearity error, the other probe takes over, the overlap is associated to the linearity criteria, as the two probes should be in functionality points simultaneoulsly (when one probe is at the extremity end of one curve, the other one should be in the linear zone of the second curve), which ensures measurement continuity (figure 19).

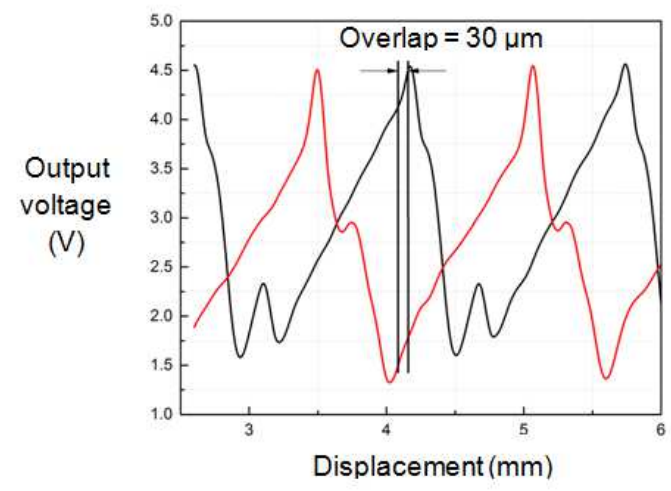

Figure 19. Measurement of the grating displacement (mm). 
In a second time, the translational movement was coupled with the movement of the spindle; to determine the optimal translational and rotational velocities applied for the motion, respectively. Figure 20 illustrates the experimental measurement obtained for $\mathrm{V}_{\mathrm{t}}=0.2 \mathrm{~mm} / \mathrm{s}$, associated with $\mathrm{V}_{\mathrm{r}}=0.5 \mathrm{rev}$. $/ \mathrm{s}$, where the signal has been filtered, by taking the average between every 40 points in the experimental curve.

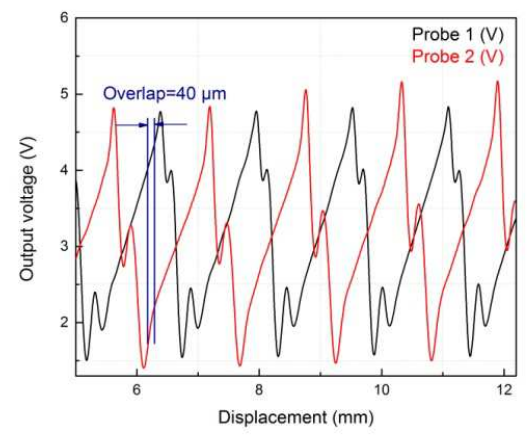

Figure 20. Signals obtained from the two fiber-optic probes for a coupled motion (translation+rotation).

It is observed that the two signals don't have the same amplitude, due to the slight differences in the intrinsic characteristics of the fiber-optic probes. A maximum linearity error of $5 \%$ was needed, to get a sufficient overlap between two successive signals. 
The experimental results have been analyzed, by calculating the linear sensitivity and the corresponding measurement range on each conical step. The linear displacement was generated by the high precision lathe, the grating was fixed on the spindle, the Z-slideway was translated at a specified distance, which is the desired displacement, the acquisition had been done via LABVIEW, which gave the output voltage on each step of the grating. The result for the sixth step is provided in the following figure.

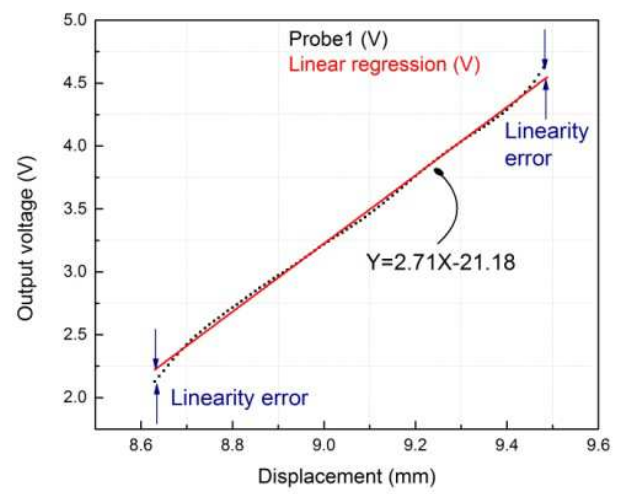

Figure 21. Signal obtained on the sixth conical step.

As seen from the previous figure the linear sensitivity obtained from the first probe on the sixth conical step is $2.71 \mathrm{~V} / \mathrm{mm}$, the corresponding measurement range is $0.858 \mathrm{~mm}$. The linearity error is at its maximum value on the extremity of the curve (figure 22). 


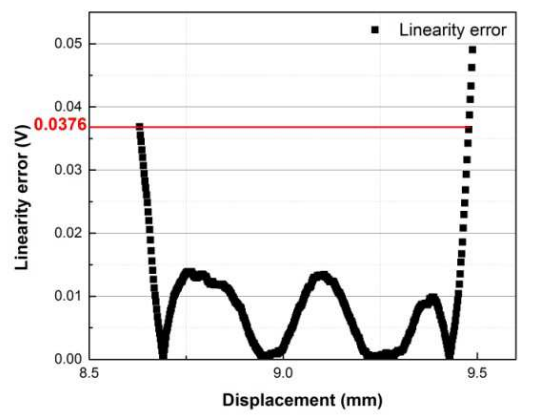

Figure 22. Linearity error as a function of displacement.

As seen from the previous figure, the linearity error on the first extremity of the step is $3.76 \%$ and at its maximum value at the other extremity $(5 \%)$, however, this error is always less at the middle of the step.

Other experimental results have been obtained at different values for the translational and the angular velocities, where the maximum rotational velocity was 20 rev./s. Figure 18 shows the displacement measurement obtained at $V_{t}=0.05$ $\mathrm{mm} / \mathrm{s}$ associated with a rotational velocity of $20 \mathrm{rev} . / \mathrm{s}$. An overlap of $30 \mu \mathrm{m}$ was needed to switch between the two fiber-optic probes; this overlap is a function of the translational velocity and the sampling frequency. For a rotational velocity of $20 \mathrm{rev} . / \mathrm{s}$, the periodic peaks due to the off-centered axes are attenuated. 


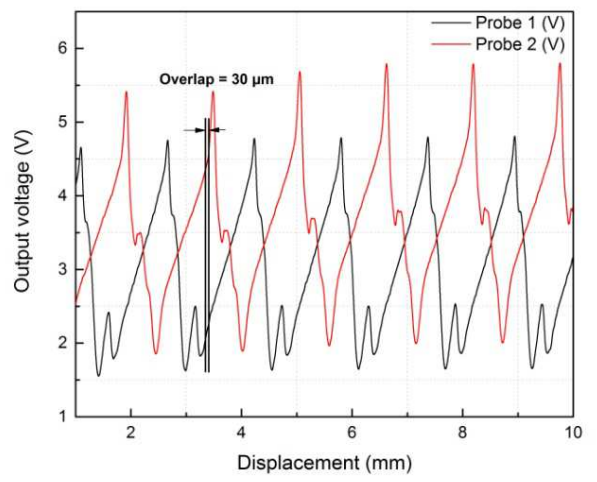

Figure 23. Signals obtained at $\left(V_{t}=0.05 \mathrm{~mm} / \mathrm{s}\right.$ and $V_{r}=20$ rev./s $)$.

The sensor resolution was evaluated in-situ on the lathe: firstly, when the machine was stopped, to determine the electronic noise of the sensor; secondly when the machine was functioning, to assess the influence of the vibrations of the lathe.

The amplitude of the sensor electronic noise (lathe stopped) was (0.3-0.4 $\mu \mathrm{m})$. Afterward, measurements were made, while the machine was functioning, but its axes remained stationary. Some oscillations of the signal, due to the flow of the oil through the slideways and also due to the numerical control, were registered.

Finally, lateral displacements have been carried out to determine the limit of resolution for the sensor in its lateral configuration use. Lateral displacements and non-axial displacements have been chosen, as the sensor is used in its lateral case because it is the configuration where high measurement ranges are obtained.

The first displacement of $(17 \pm 0.002) \mu \mathrm{m}$ was made by moving the $\mathrm{z}$-axis; it is measured by the sensor (figure 24). Taking into account the noise due to the vibrations of the machine it can be seen that the noise is about $10 \mu \mathrm{m}$, so the sensor resolution is around $10 \mu \mathrm{m}$ as it is the minimum value detectable by the sensor. 


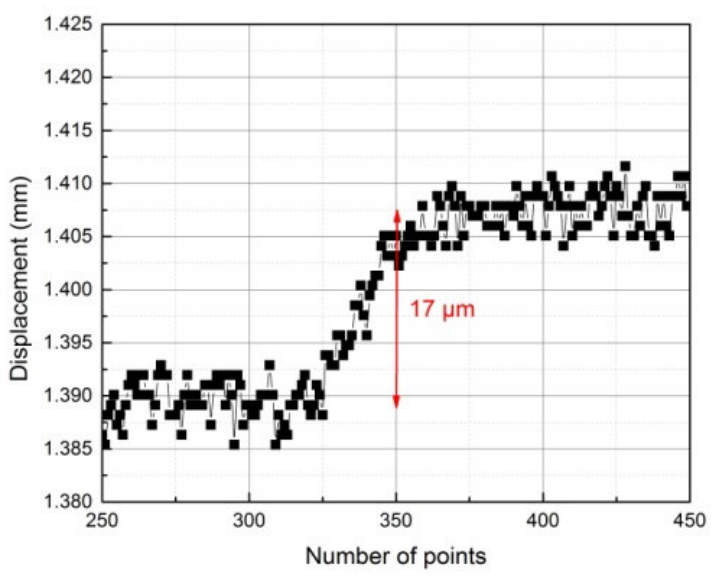

Figure 24. Resolution measurement.

As seen from the experimental results, the sensor functionality is verified successfully, with needs to improvements regarding the resolution.

\section{Conclusion and perspectives}

An optical fiber displacement sensor for helicoidal movements has been designed and fabricated. The reflector part of this sensor is a cones'-assembled grating. Firstly, a geometric model for each step of the grating was done. The objective of this model was to figure out the optimal performances of the sensor, regarding, its measurement range and the corresponding resolution.

The cones-assembled grating was precisely manufactured, in the objective to get the desired theoretical values of the grating dimensions as well as a low roughness and flatness values for the surface. 
The fabricated grating was characterized regarding its geometric parameters and its surface roughness and flatness, where a good agreement was obtained between the theoretical parameters and the measurements.

Finally, the unbalanced rotation phenomenon was characterized by one fiber-optic sensor; this phenomenon leads to having periodic peaks in the voltage output signal of the sensor. This phenomenon is attenuated at high velocities of the conesassembled grating whereas; at low speeds, the experimental curve has to be filtered. The sensor functionality was verified experimentally, in-situ on the lathe, to simulate a helicoidal motion. As a result, a micrometric resolution limit of $10 \mu \mathrm{m}$ is approached over a range of $5 \mathrm{~mm}$ measured on six cones of the grating.

As seen from the obtained results, the measurement principle has been validated on several millimeters with a micrometric resolution. The sensor can be used in industrial applications for on-line measurements and error motion detection in drilling operations simultaneously; which have not been found elsewhere in the literature.

This study showed a first research phase study, the sensor developed has been tested only on a laboratory fabrication machine, the product has not been tested somewhere else, which proves the validity commericially.

For future work, the sensor resolution has to be improved to a sub-micrometric level, by reducing the electronic noise and the oscillations due to the machine vibrations. 


\section{REFERENCES}

[1] Omron, http: //industrial.omron.fr.

[2] T. Santoso, W. P. Syam, S. Darukumalli and R. Leach, Development of a compact focus variation microscopy sensor for on-machine surface topography measurement, Measurement 187 (2022), 110311.

[3] Z. Chen, Z. Wang, M. Ren, X. Zhang, L. Zhu, X. Jiang, Development of an onmachine measurement system for ultra-precision machine tools using a chromatic confocal sensor, Precision engineering 74 (2020), 232-241.

[4] L.R. Graves, G.A. Smith, D. Apai and D.W. Kim, Precision optics manufacturing and control for next-generation large telescopes Nanomanufacturing and Metrology 2 (2019), 65-90.

[5] Y.L. Chen, Z. Niu, D. Matsuura, J.C. Lee, Y. Shimizu, W. Gao, J.S. Oh, C.H. Park,

Implementation and verification of a four-probe motion error measurement system for a large-scale roll lathe used in hybrid manufacturing, Meas. Sci. Technol. 28 (2017), 105004.

[6] D. Li, C.F. Cheung, M. Ren, D. Whitehouse, X. Zhao, Disparity pattern-based autostereoscopic 3D metrology system for in situ measurement of microstructured 
surfaces, Opt. Lett. 40 (2015), $5271-5274$.

[7] X. Zou, X. Zhao, G. Li, Z. Li, T. Sun, Non-contact on-machine measurement using a

chromatic confocal probe for an ultra-precision turning machine, Int. J. Adv.

Manuf. Technol. 90, (2017) 2163 - 2172.

[8] D. Li, X. Jiang, Z. Tong, L. Blunt, Development and application of interferometric on-machine surface measurement for ultraprecision turning process, ASME - J. Manuf. Sci. Eng. 14 (2019), 014502.

[9] W.-G. Xie, Y.-N. Zhang, P.-Z. Wang and J.-Z. Wang, Optical Fiber Sensors Based on Fiber Ring Laser Demodulation Technology, Sensors, 2018, 505.

[10] H. Zhang, D. Anders, M. Loser, S. Ihlenfeldt, J. Czarske, R. Kuschmierz, Noncontact bi-directional tool tip vibration measurement in CNC milling machines with a single optical sensor, Mechanical Systems and Signal Processing, 2020, 106647. [11] F. Zhou, W. Duan, X. Li, J.-T. Tsai, M.B.G. Jun, High precision in-situ monitoring of electrochemical machining process using an optical fiber Fabry-Pérot interferometer sensor, Journal of Manufacturing process, 2021, 180-188.

[12] S. Takushima, H. Kawano, H. Takahara and T. Kurokawa, On-machine multidirectional laser displacement sensor using scanning exposure for high-precision measurements of metal-works, Precision engineering 51 (2018) 437-444. 
[13] J. Abir, S. Longo, P. Morantz and P. Shore, Virtual metrology frame technique for improving dynamic performance of a small size machine tool, Precision engineering 48 (2017); 24-31.

[14] Y. He, X. Zhang, L. Zhu, G. Sun, X. Lou, M. Dong, Curvature and force measurement of soft manipulator based on stretchable helical optic fibre, Optical fiber technology, 2019.

[15] A. KHIAT, Capteurs à fibres optiques pour la mesure à haute résolution de déplacements linéaires et angulaires sur une grande étendue. Application aux systèmes mécaniques de dimensions réduites, Mémoire de thèse, UTC, 2007.

[16] C. Prelle, F. Lamarque and P. Revel, Reflective optical sensor for long-range and high-resolution displacements, Sensors and Actuators (2006) 139-146.

[17] A. KHIAT, Capteurs à fibres optiques pour la mesure à haute résolution de déplacements linéaires et angulaires sur une grande étendue. Application aux systèmes mécaniques de dimensions réduites, Mémoire de thèse, UTC, 2007.

[18] Rawashdeh, Z. E., F. Lamarque, C. Prelle and P. Revel, Influence of the Grating of Cones Shape on the Performances of Fiber-Optic Linear Displacement Sensor, REM-mecatronics, paris, 2012.

[19] A. Khiat, F. Lamarque, C. Prelle, Ph. Pouille, M. Leester-Schadel and S. Büttgenbach, Two-dimension fiber optic sensor for high-resolution and long range linear measurements, Sensors and Actuators (2010) 43-50. 
[20] R. Zhu, R. Jing, Y Cheng, Simulation and experimental studies of a doublefiber angular displacement sensor, Optics \& Laser Technology (2017) 168-172.

[21] Z. El Rawashdeh, P. Revel, C. Prelle, F. Lamarque, Fiber-optic sensor for long range displacement measurement of a rotating spindle. Mecatronics rem Compiègne, France, June 2016.

[22] Z. El Rawashdeh, P. Revel, C. Prelle, F. Lamarque. Cones assembled grating for long range fiber-optic linear displacement sensor, $3^{\text {rd }}$ international conference on Photonics, optics and laser technology, Berlin 2015.

[23] A. Gautier, H. Khanfir, P. Revel, R.Y. Fillit, Polish miror finish surfaces obtained by high precision turning, Int. J. Machining and Machinability of Materials, Vol. 4 (2008).133-147. 